\title{
ADVANCES IN ELECTRODE MATERIALS RESEARCH
}

\author{
S. Y. HUANG, G. CAMPET* \\ Laboratoire de Chimie du Solide du CNRS, Université Bordeaux I, 351 cours de la \\ Libération, 33405 Talence Cedex, France \\ H. S. DWEIK \\ AL-Quds University, College of Science \& Technology, Jerusalem; West Bank
}

(Received November 20, 1994; in final form November 30, 1994)

\section{INTRODUCTION}

The technologies of primary (non-rechargeable) and secondary (rechargeable) lithium batteries have been developed in parallel to the developments in the microelectronics industry for about 20 years. ${ }^{1}$ The lithium batteries can be the lightest and most compact power sources when they are intended for portable equipment such as watches, calculators, cameras, cordless telephones, computers, and so on.

During the past 10 years, the worldwide "green revolution" has requested a new, clear, and noiseless system of energy storage for replacing petrol. Rechargeable lithium batteries as high power and high energy density devices can also meet the requirements of clear and noiseless energy source, especially in the development of electric vehicles. Consequently, rechargeable lithium batteries with high power and long-life cycles have been very attractive to research groups all over the world. ${ }^{1}$

Thermodynamically, an electrochemical e.m.f. system is generated if an electrolyte is sandwiched between two electrode materials with different chemical potentials. Electrodynamically, if a constant supply of ions can be maintained and transported through the electrolyte, this system will deliver current when connected across a load circuit. In the beginning of the research on rechargeable lithium batteries, a simple effect system has been studied. As a $\mathrm{Li}$ intercalation compound consists of a host $\langle\mathrm{H}\rangle$ matrix into/from which $x$ guest ions $\mathrm{Li}^{+}$may be inserted/extracted reversibly without a rearrangement of the host structure, a simple lithium battery may be represented as:

Anode $\Theta \mathbf{L i} / \mathbf{L i}^{+} / \mathbf{L i}_{x} \mathbf{H} \oplus$ Cathode.

If $\phi_{A}$ and $\phi_{B}$ represent the anode and cathode work functions respectively, the open-circuit voltage $V_{o c}$ can be expressed as:

$\mathrm{V}_{\mathrm{oc}}=\left(\phi_{A}-\phi_{B}\right) / e_{0}$,

\footnotetext{
*Present address: Institut de Chemie de la Matièra Condensée de Bordeaux, CNRS, Université Bordeaux I, Chateau Brivazac, Ave du Dr. A. Schweitzer, 33600 Pessac, France.
} 
where $e_{0}$ designates the electronic charge. However, the use of lithium metal as the negative electrode in rechargeable cells introduces some problems. First, the dendritic deposition of lithium metal upon recharging causes internal short-circuits and occasionally may cause explosion of these cells. Second, the freshly deposited lithium dendrites react with the electrolyte and become isolated from the bulk lithium metal resulting in lower coulombic efficiencies of lithium electrodes and poor cycling life. ${ }^{2}$ These problems can be circumvented if another lithium intercalation compound $\left(\mathrm{Li}_{x} \mathrm{H}\right)$ is used as the negative electrode instead of the limited rechargeability and the safety hazards of lithium metal. Therefore, a "double effect" system of so-called "rocking-chair" has been proposed since $1980 ;{ }^{3-8}$ it can be illustrated as:

Anode $\Theta \mathrm{Li}_{x} \mathrm{H}_{1} / \mathrm{Li}^{+} / \mathrm{Li}_{y} \mathrm{H}_{2} \oplus$ Cathode.

The lithium intercalation potential of the anode material $\mathrm{Li}_{x} \mathrm{H}_{1}$ is generally more negative than that of the cathode material $\mathrm{Li}_{x} \mathrm{H}_{2}$. In fact, the potential $\mathrm{V}_{o c}$ of the rocking-chair cells should be the difference between the chemical potential of lithium in the host structures $\left\langle\mathrm{H}_{1}\right\rangle$ and $\left\langle\mathrm{H}_{2}\right\rangle$, respectively. $\mathrm{V}_{\mathrm{oc}}$ can also be estimated using equation (2); it is depicted in the schematic energy diagram shown in figure 1. For instance, $\mathrm{V}_{\mathrm{oc}}$ can be as high a $\sim 4 \mathrm{~V}$ for a "rocking chair" battery using $\mathrm{Li}_{x} \mathrm{C}$ as $\left\langle\mathrm{H}_{1}\right\rangle$ and $\mathrm{Li}_{1-x} \mathrm{CoO}_{2}$ as $\left\langle\mathrm{H}_{2}\right\rangle$.

Fig. 2 depicts some electrode potentials measured vs. a lithium electrode.

In fact, the main battery requirements for efficient energy storage are ideally: (i) high energy density ( $>300 \mathrm{Wh} / \mathrm{l}$ ); (ii) high specific energy ( $>300 \mathrm{Wh} / \mathrm{kg}$ ); (iii) high specific power ( $>150 \mathrm{~W} / \mathrm{kg}$ ); (iv) long life (cyclability $>1000$ cycles); (v) safety for the user.

These performances obviously depend not only upon the structure and the texture of the electode materials, but also on the nature of the constitutive atoms. In this paper, we firstly describe the structural and textural effects that influence the electrochemical properties of the electrode materials; then a correlation between the open-circuit voltage and the electronic energy configuration of the electrode materials is reported, accounting for their electrochemical behavior.

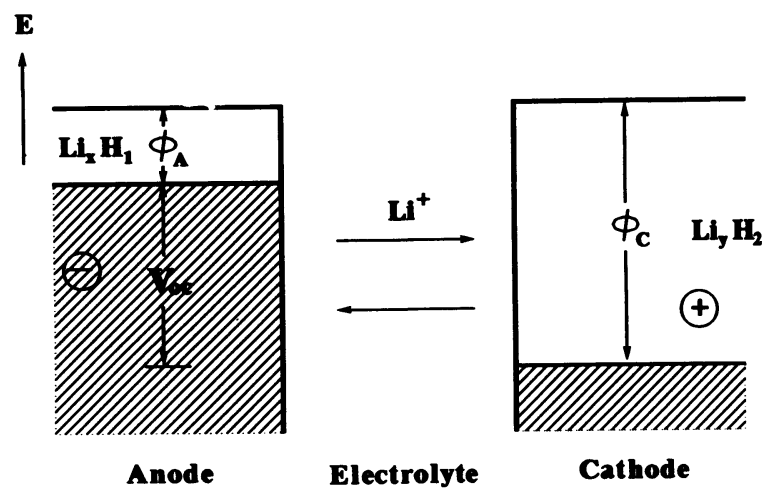

FIGURE 1 Schematic energy diagram of a "rocking-chair" cell at open circuit. 


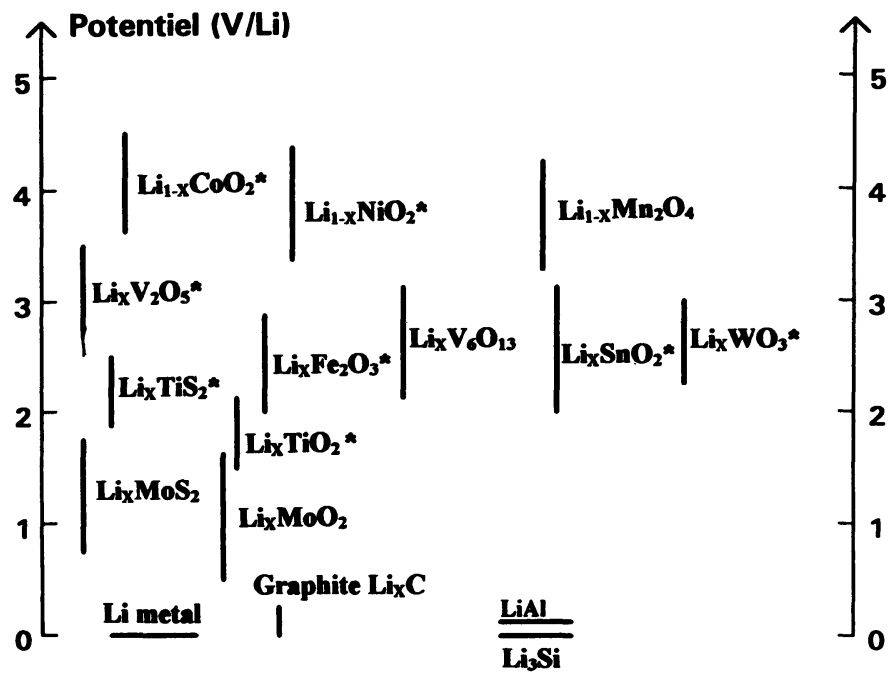

FIGURE 2 Comparison between the open circuit potentials of different electrode materials.

*Compounds prepared and studied at the "Laboratoire de Chimie du Solide-Université de Bordeaux."

\section{STRUCTURAL AND TEXTURAL CONSIDERATIONS}

\section{II.1. STRUCTURAL CONSIDERATIONS}

The technology of lithium batteries has been developed on the basis of the lithium intercalating material research. In many cases, when the electrode is based on inorganic materials, its capacity, insertion rate of lithium, and reversibility are related to its crystal structure host. The classification of host structures is generally represented as: ${ }^{9}$

Host structures $\left\{\begin{array}{c}\text { layered hosts, ex: } \mathrm{Li}_{1-x} \mathrm{MO}_{2}(\mathrm{M}=\mathrm{Co}, \mathrm{Ni}) \text { and } \mathrm{Li}_{x} \mathrm{~V}_{2} \mathrm{O}_{5} \\ \text { framework hosts }\left\{\begin{array}{l}1 \mathrm{D} \text { tunnels, ex: } \mathrm{WO}_{3} \text {-tetrag. and hexag. } \\ 2 \mathrm{D} \text { tunnels, ex: } \mathrm{TiO}_{2} \text {-anatase } \\ 3 \mathrm{D} \text { tunnels, ex: } \mathrm{Li}_{1-x} \mathrm{M}_{2} \mathrm{O}_{4} \text {-spinels } \\ (\mathrm{M}=\mathrm{Ti}, \mathrm{Mn})\end{array}\right.\end{array}\right.$

1.a. Layered oxides: $\mathrm{Li}_{1-x} \mathrm{MO}_{2}(\mathrm{M}=\mathrm{Co}, \mathrm{Ni})$ and $\mathrm{Li}_{x} \mathrm{~V}_{2} \mathrm{O}_{5}$ are presented as illustrative examples.:

In the layered oxides $\mathrm{Li}_{1-x} \mathrm{MO}_{2}(\mathrm{M}=\mathrm{Co}, \mathrm{Ni}$ ) (Fig. 3), the $\mathrm{Li}$ and $\mathrm{M}$ atoms occupy alternate (111) planes of the rocksalt structure. The O-M-O layers are bonded electrostatically via the interlayer $\mathrm{Li}^{+}$ions. The latter remain in octahedral coordination over the entire range of stability of the $\mathrm{Li}_{1-x} \mathrm{MO}_{2}$ system. Let us note that the research on $\mathrm{LiCoO}_{2}$ is probably more advanced than for $\mathrm{Li}_{1-x} \mathrm{NiO}_{2}$ because of the simplicity of preparing the former material. ${ }^{10}$ However, the rechargeable capacity of $\mathrm{LiCoO}_{2}$ is limited to less than $150 \mathrm{mAh} \cdot \mathrm{g} \cdot{ }^{11}$ In fact, the layered structure becomes more unstable as $x \rightarrow 1$ because the Van der Waals 


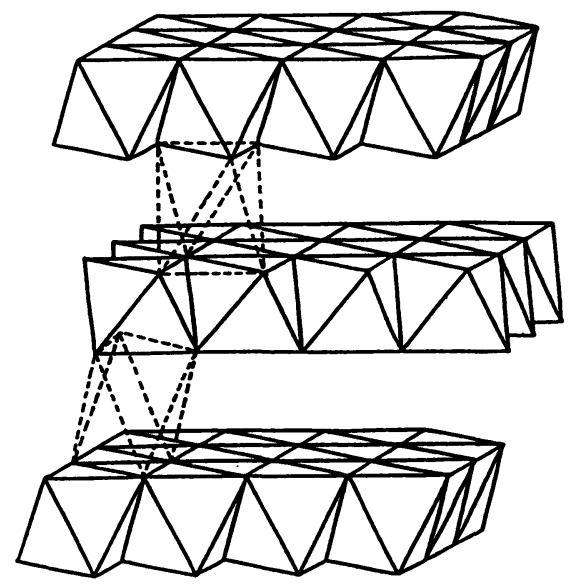

FIGURE 3 Schematic representation of the $\mathrm{Li}_{1-x} \mathrm{MO}_{2}$ layered structure.

forces between the oxide-ion layers tend to be weaker than the electrostatic repulsive forces. ${ }^{12}$ Consequently, attempts are being done, at the present time, to stabilize the layered structure using appropriate dopings, such as polymer-based pillars between the layers. Another approach, so called "textural approach" presented in the next section, might also be advantageously used. ${ }^{13} \mathrm{LiNiO}_{2}$ prepared by the same method as described for $\mathrm{LiCoO}_{2}{ }^{10}$ exhibits poor rechargeable capacity due to contamination of structural disorder in the matrix..$^{10,14-16}$ For instance, a 50\% displacement of nickel ions at 3(a) sites and lithium ions at 3(b) sites gives a rock-salt type $\mathrm{LiNiO}_{2}$, which is electrochemically inactive because of the immobile lithium ions at the octahedral sites in the matrix. On the other hand, a $25 \%$ regular displacement between $3(\mathrm{a})$ and 3(b) sites gives a spinel-framework structure in which lithium ions supposedly can move from one site to the other as in $\mathrm{LiMn}_{2} \mathrm{O}_{4} \cdot{ }^{17} \mathrm{~T}$. Ohzuku et $\mathrm{al}^{10}$ succeeded in preparing electrochemically strongly active $\mathrm{LiNiO}_{2}$ electrodes using proper processing methods. For instance, $\mathrm{LiNiO}_{2}$ prepared from $\mathrm{LiNO}_{3}$ and $\mathrm{NiCO}_{3}$ or $\mathrm{Ni}(\mathrm{OH})_{2}$, exhibited a rechargeable capacity as high as $200 \mathrm{mAh} \cdot \mathrm{g}^{-1}$ within 2.5 and $4.1 \mathrm{~V}$ vs. $\mathrm{Li}$ (corresponding to $x=0.72$ in $\mathrm{Li}_{1-x} \mathrm{NiO}_{2}$ ).

Let us note that the open circuit voltage is lower for $\mathrm{Li}_{1-x} \mathrm{NiO}_{2}$ than for $\mathrm{Li}_{1-x} \mathrm{CoO}_{2}$ (fig. 4), implying a lower working voltage for the former electrode. ${ }^{18}$ However, we have seen that better results are obtained with $\mathrm{Li}_{1-x} \mathrm{NiO}_{2}$ than for $\mathrm{Li}_{1-x} \mathrm{CoO}_{2}$, especially when rechargeable capacity or long term cyclability are concerned. ${ }^{10-17,19}$

The vanadium-oxygen system has been intensively studied because some of the compounds (such as the pseudolayered $\mathrm{V}_{2} \mathrm{O}_{5}$ or three-dimensional $\mathrm{V}_{6} \mathrm{O}_{13}$ phases) are also promising intercalation electrode candidates for room temperature rechargeable $\mathrm{Li}$ batteries. ${ }^{20,21,22}$ For instance, $\mathrm{V}_{6} \mathrm{O}_{13}$ can reversibly intercalate up to one $\mathrm{Li}$ per vanadium atom, and it is being developed widely in polymer prototype rechargeable $\mathrm{Li}$ batteries. As for the vanadium bronzes of general formula $\mathrm{Li}_{x} \mathrm{~V}_{2} \mathrm{O}_{5}$, their structure is strongly dependent upon both the synthesis conditions and the lithium content $(x)$. The phase diagram of the Li-based 


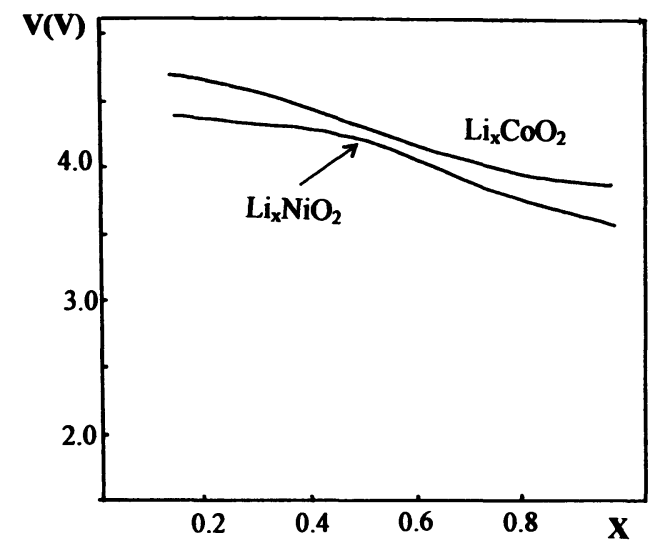

FIGURE 4 Open-circuit discharge curve for $\mathrm{Li}_{1-x} \mathrm{CoO}_{2}$ and $\mathrm{Li}_{1-x} \mathrm{NiO}_{2}{ }^{18}$

vanadium oxide system, established by room temperature insertion of $\mathrm{Li}$ into the the pseudo-layered $\mathrm{V}_{2} \mathrm{O}_{5}$, consists of several phases denoted by $\alpha, \varepsilon, \delta$ and $\omega-\mathrm{Li}_{x} \mathrm{~V}_{2} \mathrm{O}_{5},{ }^{23,25}$ whose structures are closely related to that of $\mathrm{V}_{2} \mathrm{O}_{5}{ }^{26}$ The $\omega-\mathrm{Li}_{x} \mathrm{~V}_{2} \mathrm{O}_{5}$ phase, which reversibly intercalates two lithium ions per $\mathrm{V}_{2} \mathrm{O}_{5}$ between 4 and $1.9 \mathrm{~V}$, has been proposed as a new cathode for rechargeable lithium batteries. ${ }^{27}$ The $\alpha$ phase $\left(0<x<0.1\right.$ in $\left.\mathrm{Li}_{x} \mathrm{~V}_{2} \mathrm{O}_{5}\right)$ can also be stabilized from solid state-state reactions above $350^{\circ} \mathrm{C}$. Moreover, by increasing the amount of lithium above 0.1 , one still gets, from solid state reactions, new phases such as the $\gamma$-phase (fig. 5). In fact, $\gamma-\mathrm{Li}_{x} \mathrm{~V}_{2} \mathrm{O}_{5}$ exists within the range of composition $0.88<x<1$; moreover, it has a structure ${ }^{28}$ that allows for the electrochemical removal of lithium topotactically so that a new $\mathrm{V}_{2} \mathrm{O}_{5}$ phase was obtained and denoted as $\gamma^{\prime}-\mathrm{Li}_{x} \mathrm{~V}_{2} \mathrm{O}_{5}{ }^{29}$ This new phase was demonstrated to be a promising positive electrode material for rechargeable $\mathrm{Li}$ batteries (fig. 6).

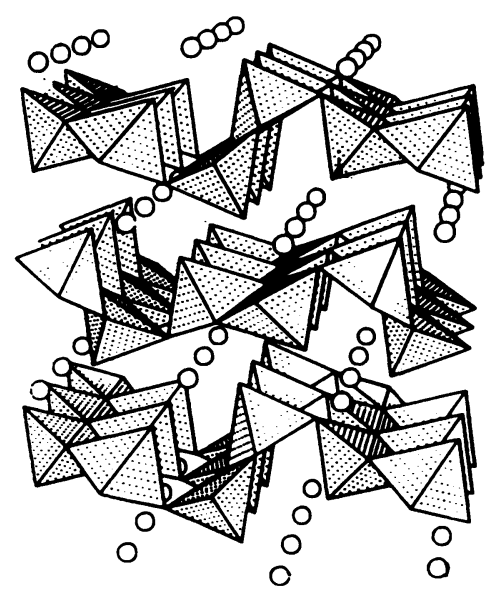

FIGURE 5 The $\gamma-\mathrm{Li}_{x} \mathrm{~V}_{2} \mathrm{O}_{5}$ structure. 


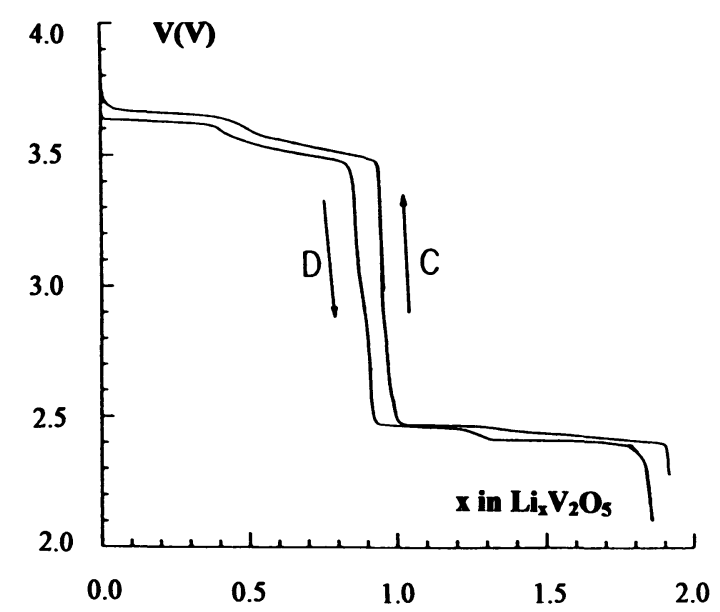

FIGURE 6 Second and third discharge of a $\mathrm{Li} / / \gamma-\mathrm{Li}_{x} \mathrm{~V}_{2} \mathrm{O}_{5}$ cell between $3.8 \mathrm{~V}$ and $2 \mathrm{~V}$ at 0.25 $\mathrm{mA} / \mathrm{cm}^{2} .27$

1.b. Tunnel framework oxides: $\mathrm{WO}_{3}, \mathrm{TiO}_{2}, \mathrm{Li}_{1-x} \mathrm{M}_{2} \mathrm{O}_{4}(M=\mathrm{Ti}, \mathrm{Mn})$ are presented as illustrative examples.:

The tetragonal and hexagonal tungsten-bronze structures contain isolated, parallel 1D tunnels into which the mobile ions are constrained. However, the 1D tunnels, as they occur in tetragonal and hexagonal $\mathrm{WO}_{3}$, are often blocked by stacking faults that hinder the ionic conductivity. Consequently, more attention has been given to ionic conductors having $2 \mathrm{D}$ and $3 \mathrm{D}$ tunnels. For instance, the lithium insertion rate, reversibly exchanged, can be as high as $x=0.8$ for $\mathrm{TiO}_{2}$ anatase, which has a 2D tunnel structure. ${ }^{13}$ The cubic $\mathrm{Li}_{1-x} \mathrm{M}_{2} \mathrm{O}_{4}(\mathrm{M}=\mathrm{Ti}, \mathrm{Mn})$ spinels offer interesting examples of a 3D tunnel structure: the $M$ cations occupying half of the octahedral sites and the other empty octaheral sites, to which the $\mathrm{Li}^{+}$ions have access, form an interconnected 3D array of edge-shared sites. ${ }^{12}$ The dimensions of the spinel host are held rigid in 3D by strong $\mathrm{M}-\mathrm{O}$ bonding, so it is possible to insert or extract $\mathrm{Li}^{+}$ions at room temperature to obtain $\mathrm{Li}_{1-x} \mathrm{M}_{2} \mathrm{O}_{4}$ $(0 \leq x<1)$ without disrupting the $\left[\mathrm{M}_{2}\right] \mathrm{O}_{4}$ array. ${ }^{12,30}$ Let us note that the system $\mathrm{Li}_{1-x} \mathrm{Mn}_{2} \mathrm{O}_{4}$ has also been investigated: a two-phase (cubic-tetragonal) region exists in the compositional range $0.1 \leq x \leq 0.8$, so that the open-circuit voltage is advantageously independant of $x .^{12}$

Finally, cathodes of composition $\mathrm{Li}_{1+x} \mathrm{Mn}_{2} \mathrm{O}_{4}$, which are synthesized using an original method (reduction of lithium-manganese-oxide and manganese-oxide precursors with hydrogen at $300^{\circ} \mathrm{C}$ to $350^{\circ} \mathrm{C}$, and with carbon at $600^{\circ} \mathrm{C}$ ) are even more tolerant to repeated lithium insertion and extraction. ${ }^{31}$

\section{1.c. What would be the three most efficient cathode materials?:}

The above remarks show that the most promising cathode materials, for secondary lithium batteries of high specific energy, would be $\mathrm{Li}_{1-x} \mathrm{MO}_{2}(\mathrm{M}=\mathrm{Co}$ or and $\mathrm{Ni})$, $\mathrm{Li}_{1 \pm x} \mathrm{Mn}_{2} \mathrm{O}_{4}, \mathrm{Li}_{x} \mathrm{~V}_{2} \mathrm{O}_{5}, \mathrm{Li}_{x} \mathrm{~V}_{6} \mathrm{O}_{13}$ or their solid solution (i.e.: $\mathrm{Li}_{1} \mathrm{Co}_{0.5} \mathrm{Ni}_{0.5} \mathrm{O}_{2}$ ). 
The high oxidizing power of the involved redox couples $\mathrm{O}^{3+/ 4+}, \mathrm{Ni}^{3+/ 4+}, \mathrm{Mn}^{3+/ 4+}$, $\left.\mathrm{V}^{3+/ 4+}, \mathrm{V}^{4+/ 5+}\right)$ confer, indeed, to these oxide electrodes their high potential values (fig. 2).

\section{II.2. TEXTURAL CONSIDERATION-NANOELECTROCHEMISTRY}

The "NCIM (nano-crystallite insertion material) concept" has been recently applied by some of us in the secondary lithium battery research and it may create a new research area so called "nanoelectrochemistry".

We have shown above that the electrochemical properties of the electrode materials, such as the rate of lithium reversible exchange, depend on their crystalline structure. This phenomenum can be called "structural effect". On the other hand, if the crystallites and particle sizes are decreased to nanoscale dimensions, an additional effect called "surface effect" intervenes. We are then dealing with the NCIM concept. ${ }^{13}$

We have reported elsewhere ${ }^{13,32,33}$ that electrodes based on fine-grained transition metal oxides $\left(\mathrm{Li}_{x} \mathrm{Fe}_{2} \mathrm{O}_{3}, \mathrm{Li}_{x} \mathrm{SnO}_{2}, \mathrm{Li}_{2-x} \mathrm{NiO}_{2}\right.$, etc.) exhibit efficient electrochemical (de)insertion of $\mathrm{Li}^{+}$ions. The materials were symbolized as NCIMs. By minimizing the crystallite size, we favor, indeed, the formation of dangling and weak bonds at the surface and, thereby, the rate of lithium reversibly exchanged.

\section{ELECTRONIC CONSIDERATION}

During the electrochemical insertion, lithium ions and electrons are simultaneously introduced into the electrode material. The corresponding inserted compound must be a good mixed ionic-electronic conductor. Good electronic conductivity of the electrode is possible when the electronic charge transfers between two ions, $\mathbf{M}^{n+}$ and $M^{(n+1)+}$, which are on crystallographically, and thereby energetically, equivalent sites. The carriers (electrons or holes) are either:

(i) itinerant if a broad band is envolved in the conduction process or

(ii) polaronic if their mobility carries an activation energy; however the activation energy must be low enough in order to achieve the required high conductivity. ${ }^{9,12}$

One of these favorable situations is observed in the above quoted oxides $\mathrm{Li}_{1-x} \mathrm{MO}_{2}(\mathrm{M}=\mathrm{Co}, \mathrm{Ni})$ or $\mathrm{Li}_{1-x} \mathrm{Mn}_{2} \mathrm{O}_{4}$. These oxides have only $90^{\circ} \mathrm{M}-\mathrm{O}-\mathrm{M}$ interaction and, thereby, a rather narrow conduction band $\sigma^{*}$ of $e_{g}$ parentage. ${ }^{9,12}$ Therefore, when $e_{g}$ orbitals are involved in the conduction process, as it occurs for $\mathrm{Li}_{1-x} \mathrm{Mn}_{2} \mathrm{O}_{4}$ or $\mathrm{Li}_{1-x} \mathrm{NiO}_{2}$, we are then dealing with a small polaron semiconductor (situation (ii)). A higher conductivity (than for $\mathrm{Li}_{1-x} \mathrm{Mn}_{2} \mathrm{O}_{4}$ or $\mathrm{Li}_{1-x} \mathrm{NiO}_{2}$ ) occurs for $\mathrm{Li}_{1-x} \mathrm{CoO}_{2}$ and is related to a higher mobility; in $\mathrm{Li}_{1-x} \mathrm{CoO}_{2}$ the hole carriers are delocalized in the broad $\pi^{*}$ band of $\mathrm{Co}_{3^{+} / 4^{+}}$: $r_{2 g}$ parentage. This band results from strong CO-Co interactions across shared 
octahedral site edges inducing a direct overlapping of the Co: $t_{2 g}$ orbitals. Moreover, the (low spin) $\mathrm{Co}^{3+}: t_{2 g}^{6} e_{g}^{0}$ or $\mathrm{Co}^{4+}: t_{2 g}^{5} e_{g}^{0}$ configurations place the Fermi energy $E_{F}$, which fixes the electrode potential at equilibrium, within the broad $\pi^{*}\left(t_{2 g}\right)$ band located below the narrower $\sigma^{*}\left(e_{g}\right)$ band. Consequently, the electrode potential is slightly higher for $\mathrm{Li}_{1-x} \mathrm{CoO}_{2}$ than for $\mathrm{Li}_{1-x} \mathrm{Mn}_{2} \mathrm{O}_{4}$ or $\mathrm{Li}_{1-x} \mathrm{NiO}_{2}$.

Let us note that the top of the $\pi^{*}$ band lies well above the oxygen valence band of $2 p$ parentage. Therefore, no mobile holes that would have caused the electrode decomposition are created in this band during the deintercalation process of $\mathrm{Li}^{+}$ions in $\mathrm{Li}_{1-x} \mathrm{CoO}_{2}$. A fortiori, no mobile carriers occur in the oxygen valence band in the two other oxides $\mathrm{Li}_{1-x} \mathrm{Mn}_{2} \mathrm{O}_{4}$ and $\mathrm{Li}_{1-x} \mathrm{NiO}_{2}$ during the $\mathrm{Li}$ deintercalation process since the involved $\sigma^{*}: e_{g}$ band is located above the $\pi^{*}$ band and, therefore, above the $O^{2}: 2 p^{6}$ valence band. Such a favorable situation does not exist in the sulfides and selenides for which the top of the $\mathrm{S}^{2-}: 3 p^{6}$ band lies at higher energy than the $d$ orbitals of the $\mathrm{M}$ ions $(\mathrm{M}=\mathrm{Mn}, \mathrm{CO}, \mathrm{Ni})$. Therefore, contrary to what is observed in the oxides, only the $\mathrm{M}^{2+/ 3+}$ and not the $\mathrm{M}^{4+}$ valence states are chemically accessible in the sulfides or selenides. ${ }^{9,12}$ Consequently, the corresponding cathode materials will have a too-low potential vs $\mathrm{Li}$ and, therefore, have not drawn our attention in this paper.

Therefore, we have seen that there is a close relation between the electrochemical and electronic properties of the electrode materials. Indeed, the rate of $\mathrm{Li}^{+}$ions that can be reversibly inserted into the electrode within given potential limits obviously depends upon the concentration and distribution of the energy states available for electrons. ${ }^{34}$ Related to that, the changes of cathode potential upon $\mathrm{Li}^{+}$insertion (such as those reported in fig. 4 for $\mathrm{Li}_{1-x} \mathrm{CoO}_{2}$ and $\mathrm{Li}_{1-x} \mathrm{NiO}_{2}$ ) can correspond to Fermi level variations of the materials. Since the electronic structure of the electrode materials is connected with the overlap of the wave functions of electrons belonging to the transition metal atoms $M$, then the Fermi energy and therefore the electrode potential will depend on the M-M distance $\left(R_{\mathrm{M}-\mathrm{M}}\right)$. The latter generally increases with the increasing content of the lithium ions (thereby of the injected electrons). The increase in $R_{\mathrm{M}-\mathrm{M}}$ makes theoverlap of the wave functions of $3 d$ electrons diminish and at a critical M-M distance $\left(R_{c}\right)$, it can bring about splitting of the effective energy band. ${ }^{35}$ Such an abrupt modification of the electronic structure might manifest itself in abrupt changes of the Fermi level and therefore of potential upon $\mathrm{Li}^{+}$insertion We have also seen that the discharge curve can present a steplike character when several successive phase transitions take place in the electrode material upon lithium insertion, as it occurs for $\mathrm{Li}_{1+x} \mathrm{Mn}_{2} \mathrm{O}_{4}$. However, the consideration of the discharge character depending on the electronic structure of the semiconducting electrode is still available because $E_{F}$ changes during each phase transition. Fig. 7 illustrates schematically the expected character of the discharge curve in relation to the electronic structure of the cathode material for $R_{M-M}<$ $R_{c}$ and $R_{\mathrm{M}-\mathrm{M}}>R_{c}$. In the case of $R_{c}-R_{\mathrm{M}-\mathrm{M}}>0$, high density of states near the Fermi level can lead to monotonous characters of the discharge curve (fig. 7a). On the other hand, low density of states near $E_{F}$, as it occurs when 


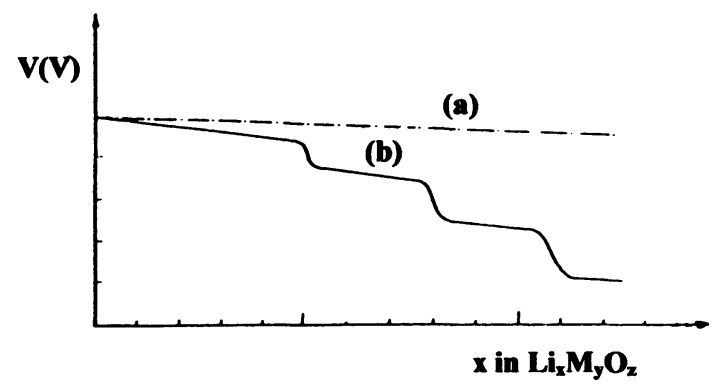

FIGURE 7 Expected character of discharge curve of cathode material for $R_{M-M}<R_{c}$ (a) and $R_{\mathrm{M}-\mathrm{M}}>R_{c}(\mathrm{~b}) .^{18}$

$R_{c}-R_{M-M}<0$, can result in a strong compositional dependence of the electrode potential vs. $x$ (fig. $7 \mathrm{~b}$ ).

\section{CONCLUSION}

It is preferable that the electrode materials have a host structure adapted to lithium intercalation, as it can occur for $\mathrm{Li}_{1-x} \mathrm{CoO}_{2}, \mathrm{Li}_{1-x} \mathrm{NiO}_{2}, \mathrm{Li}_{1-x} \mathrm{Mn}_{2} \mathrm{O}_{4}$, $\mathrm{Li}_{x} \mathrm{~V}_{2} \mathrm{O}_{5}$, or $\mathrm{Li}_{x} \mathrm{~V}_{6} \mathrm{O}_{13}$. However, when the crystallite size decreases to a nanometric scale, the structural effect would be minimized in favor of the "textural effect," i.e., the electrochemical properties would then be influenced by the density of the surface states, the specific surface area, the grain boundary, etc. It has also been noted that potential changes observed during the electrochemical intercalation are, generally, those of the Fermi level of the cathode material. ${ }^{18}$

\section{REFERENCES}

1. See for instance

J. Rouxel, Physica 99B, 3 (1980) and references therein.

M.B. Armand, Doctoral Thesis, Inst. National Polytech. de Grenoble (1978).

C. Delmas, C. Fouassier and P. Hagenmuller, J. Phys. Chem. Solids 39, 55 (1978).

J. Molenda, Solid State Ionics 21, 263 (1986).

A. Levasseur, M. Menetrier, Mar. Sci. Eng., B3, 5 (1989).

Z.I. Takehara and K. Kanamura, Electrochimica Acta., 38, 1169 (1993).

K.M. Abraham, Electrochimica Acta,., 38, 1233 (1993).

M. Broussely, F. Perton, J. Labat, R.J. Staniewicz and A. Romero, J. Power Sources, 43-44, 209 (1993).

2. E.J. Plichta and W.K. Behl, J. Electrochem. Soc., 140, 46 (1993).

3. M. Armand in 'Materials for advanced batteries', D.W. Murphy, Broodhyead and B.C.H. Steels Eds. Phenum Press, New York, 1980, p. 145.

4. M. Lazari and B. Scrosati, ibid., 127, 773 (1980).

5. J.M. Tacascon, ibid., 132, 2089 (1985).

6. S. Basu, U.S. Pat. No. 4423125 (1983).

7. Y. Nishi, H. Azuma and A. Omaru, U.S. Pat. No. 495928 (1989).

8. D. Guyomard and J.M. Tarascon, J. Electrochem. Soc., 139, 937 (1992).

9. J.B. Goodenough, A. Manthiram and B. Wnetrzewski, J. Power Sources, 43-44, 269 (1993).

10. T. Ohzuku, A. Veda and Nagayama, J. Electrochem. Soc., 140-7, 1862 (1993). 
11. T. Ohzuku, M. Kitagawa and T. Hirai, J. Ceram. Soc. Jpn., 100, 349 (1992).

12. J.B. Goodenough, M.M. Thackeray, W.I.F. David and P.G. Bruce, Revue de Chimie Minérale, t.21, 435 (1984).

13. S.D. Han, Doctoral Thesis, University of Bordeaux I (1994).

14. J.R. Dahn, V. von Sacken and C.A. Michael, Solid State Ionics, 44, 87 (1990).

15. T. Ohzuku, H. Komori, M. Nagayama, K. Sawai and T. Mirai, Chem. Express, 6, 161 (1991).

16. T. Ohzuku, A. Veda, M. Nagayama, Y. Iwakoshi and K. Sawai, Chem. Express, 7, 689 (1992).

17. T. Ohzuku, M. Kitagawa and T. Hirai, J. Elecrochem. Soc., 137, 769 (1990).

18. J. Molenda, Solid State Ionics 21, 263 (1986).

19. M. Broussely et al. J. Power Sources, 43-44, 209 (1993).

20. F. Gacia-Alvarodo, J.M. Tarascon and B. Wilkens, J. Elecrochem. Soc., 139, 3206 (1992).

21. C.R. Walk, in "Lithium Batteries," J.P. Gabano, Editor, p. 265, Academic Press, Inc., New York (1983).

22. D.W. Murphy, P.A. Christian, F.J. DiSalvo and J.N. Carides, J. Electrochem. Soc., 126, 497 (1979).

23. D.W. Murphy, P.A. Christian, F.J. DiSalvo and J.V. Waszczak, Inorg. Chem., 18, 2800 (1979).

24. P.G. Dickens, S.J. French, A.T. Hight and M.F. Pye, Mater. Res. Bull., 14, 1295 (1979).

25. C. Delmas, S. Brethes and M. Menetrier, J. Power Sources, 34, 113 (1991).

26. M.S. Whittingham, J. Electrochem. Soc., 123, 315 (1976).

27. J.M. Cocciantelli, M. Menetrier, C. Delmas, J.P. Doumerc, M. Pouchard and P. Hagenmuller, Solid State Ion., 50, 99 (1992).

28. P. Hagenmuller, Comprehensive Inorganic Chemistry, Vol. 4, p. 572-576, Pergamon Press, Ltd., Oxford (1973).

29. J.M. Cocciantelli, P. Gravereau, J.P. Doumerc. M. Pouchard and P. Hagenmuller, J. Solid State Chem., 93, 497 (1991).

30. A. Monchilov, V. Manev, A. Nassalev and A. Kozawa, J. Power Sources 41, 305 (1993).

31. R.J. Gummow and M.M Thackeray, J. Electrochem. Soc., 141, 1178, (1994). M. Zahurak and A. Santoro, Solid State Ionic, 9-10, 413 (1983).

32. G. Campet, S.J. Wen, S.D. Han, M.C.R. Shastry, J. Portier, Mat. Science and Engineering, 1318, 201 (1993).

33. S.D. Han, N. Treuil, G. Campet, J. Portier, C. Delmas, J.C. Lassègues and A. Pierre, Materials Science Forum, vols. 152-153, 217-220 (1994).

34. D.C. Johnson, H. Prakash, W.H. Zachariasen and R. Viswanathan, Mat. Res. Bull., 8, 777 (1973).

35. J.B. Goodenough, in: "Progress in Solid State Chemistry, ed. H. Reiss, Vol. 5 (Pergamon Press, Oxford, p. 279 (1971). 

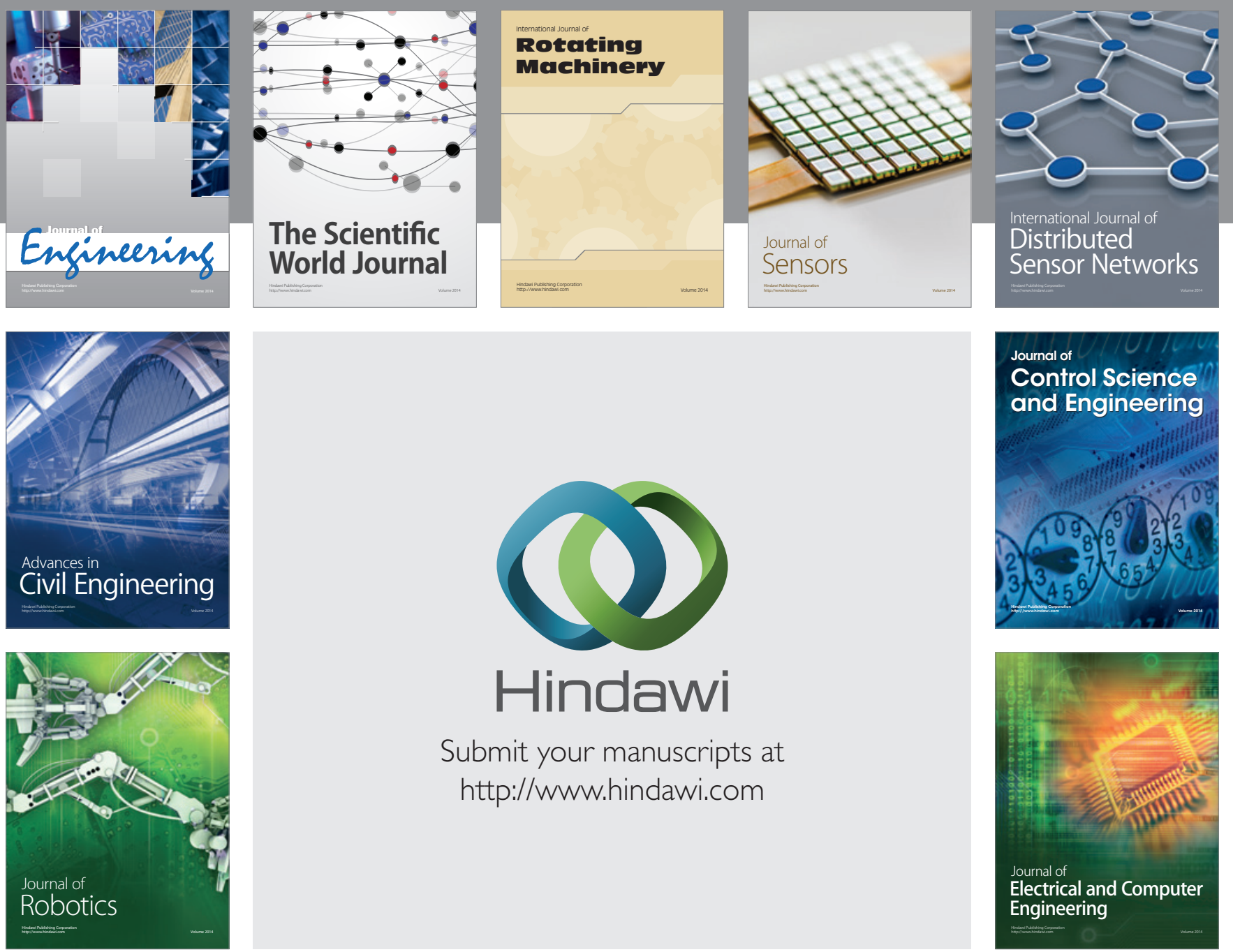

Submit your manuscripts at

http://www.hindawi.com
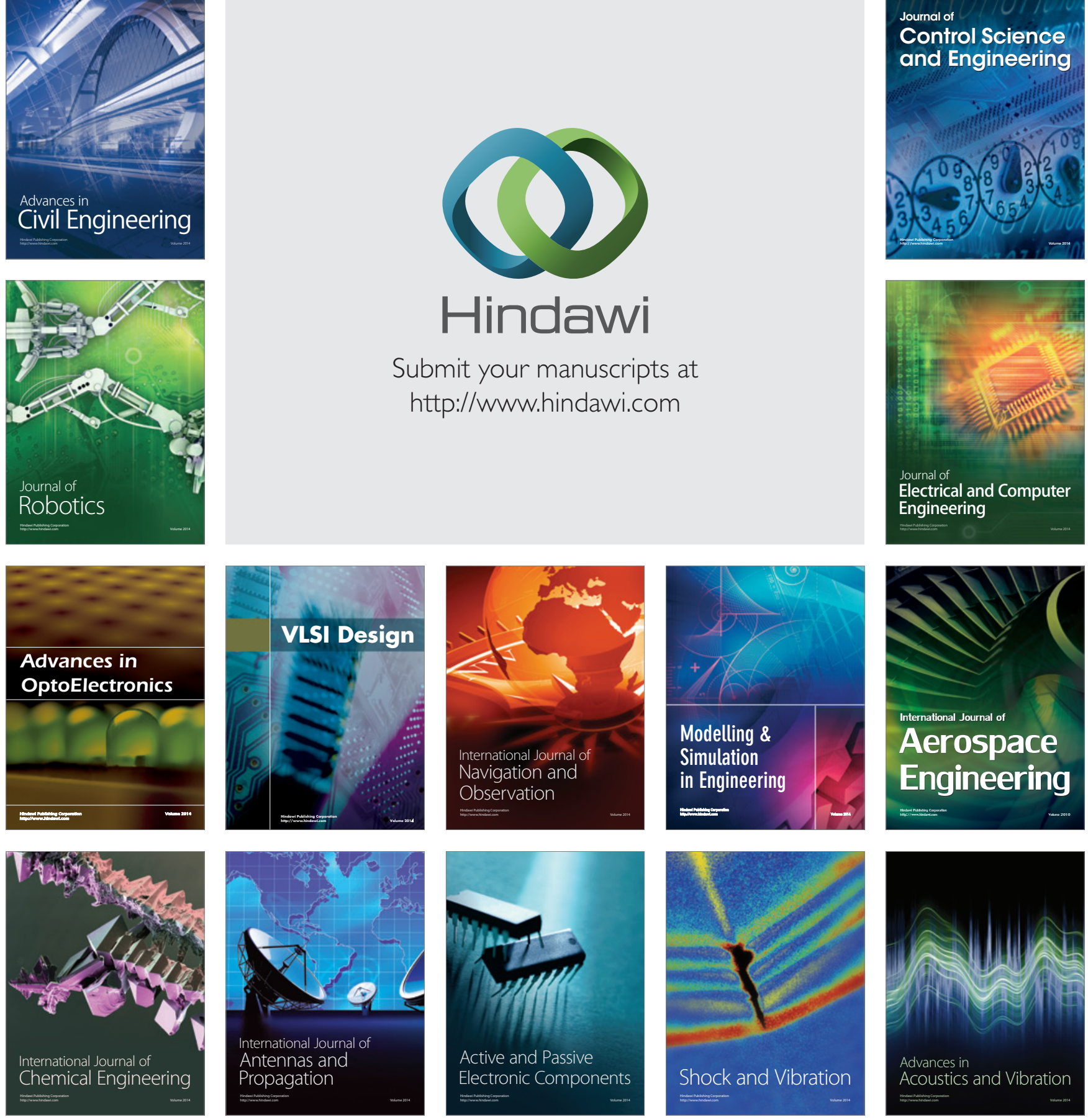